\title{
What About Inclusive Education and ICT in Italy: a Scoping Study
}

\author{
Valentina Della Volpe, PhD
}

Special Education, Italy

doi: 10.19044/esj.2016.v12n25p26 URL:http://dx.doi.org/10.19044/esj.2016.v12n25p26

\begin{abstract}
Strategies and approaches to inclusion in the classroom are important in developing a high quality, inclusive experience for students with Special Education Needs. Generally, strategies are not geared towards specific exceptionalities, but are instead designed to be implemented across exceptionality categories. Pavone (2014) and de Anna, Gaspari, Mura (2015) determined through their systematic literature review and research results that co-operation among staff, commitment and accountability to the teaching of all students, differentiation of instruction, and recognizing "that social interaction is the means through which student knowledge is developed" are key to successful inclusion of students with SEN. This paper looks at the issue of school inclusion by referring to the most recent laws about the inclusive education of students with special educational needs in Italy. Inclusive education means that all students attend and are welcomed by their neighbourhood schools in age-appropriate, regular classes and are supported to learn, contribute and participate in all aspects of the life of the school. Inclusive education is about how we develop and design our schools, classrooms, programs and activities so that all students learn and participate together. So ICT should be considered as a key tool for promoting equity in educational opportunities, that is using ICT to support the learning of learners with disabilities and special educational needs in inclusive settings within compulsory education. The paper also argues how the Italian teachers can realized good practices for inclusion through the use of ICT.
\end{abstract}

Keywords: Inclusive education - ICT - Special Education Needs

\section{Introduction}

"Inclusive education - according to UNESCO- means that the school can provide a good education to all pupils irrespective of their varying abilities. All children will be treated with respect and ensured equal opportunities to learn together. Inclusive education is an on-going process. 
Teachers must work actively and deliberately to reach its goals" (UNESCO, 2014).

All students, have the right to have equal opportunity in education (EADSNE, 2010a; United Nations. 2006; UNESCO, 2009), and to be considered as being an integral part of the learning community. Recognition of this right has recently given rise to the concept of "inclusion", which in Italy has gradually substituted that of "integration" (Della Volpe, 2014).

Inclusive education is:

a constantly evolving process of change and improvement within schools and the wider education system to make education more welcoming, learner-friendly, and beneficial for a wide range of people

- $\quad$ about restructuring education cultures, policies and practices so that they can respond to a diverse range of learners - male and female; disabled and non-disabled; from different ethnic, language, religious or financial backgrounds; of different ages; and facing different health, migration, refugee or other vulnerability challenges;

- $\quad$ about changing the education system so that it is flexible enough to accommodate any learner;

- $\quad$ an ongoing effort to identify and remove barriers that exclude learners within each unique situation;

- $\quad$ about identifying and removing barriers to learners' presence in (access to) education, participation in the learning process, and academic and social achievement;

- $\quad$ focused on solving attitude, practice, policy, environmental and resource barriers;

- a process in which all stakeholders should participate (teachers, learners, parents, community members, government policy-makers, local leaders, non-governmental organizations, etc);

- $\quad$ something that can happen outside the formal education system, as well as in formal school environments (inclusive education can happen in learning spaces that are non-formal, alternative, community-based, etc; with learners from young children through to elderly adults).

Inclusion is actually a much stronger concept which refers to "the right to belong to the mainstream"; leaving behind the idea that only few learners have "special needs", the social model of inclusion rather suggests that all students as individual learners present their own peculiar characteristics and have their own specific educational needs. Such a perspective implies a Copernican revolution which brings all students at the very heart of the educational process whilst the school is required to adjust and change in order to enable each of them to participate in the life of the school to the best of their abilities (de Anna, 2014a, 2014b, 2015; Mura, 2012). 
Inclusion should, then, be regarded as a long-lasting process which requires time, effort, competence and strong conviction by all those involved in students' education, first and foremost, by teachers (de Anna, 2014c).

The key role of teachers in giving birth to and maintaining a truly inclusive classroom is unquestionable (de Anna, Gaspari, Mura, 2015), but such an important mission also requires that suitable, effective and barrier-free educational means should be employed.

From this perspective, ICT resources are promising; there are grounds for maintaining that they help most students overcome barriers to learning, thus increasing their school achievement, together with their autonomy, willingness and self esteem.

Indeed, educational research provides strong evidence that: "ICT is both a medium and a powerful tool in supporting inclusive practice. It provides wide-ranging support for communication, assisting many learners to engage with learning, including those who are hard to reach, and helps to break down some of the barriers that lead to under-achievement and educational exclusion"(Becta, 2004, 2007; Della Volpe, 2016).

In the following, it is argued that use of ICT tools can (may) help teachers to make effective their teaching in order to support all students' full inclusion.

We begin with an analysis of the most recent laws about the inclusive education of students with special educational needs in Italy, and then we explore main educational and technological tools which replaces or facilitate the performance required in the deficient ability of the students with SEN.

\section{ICT implementation in compulsory education for students with Special Educational Needs}

In the month of January 2013, the Ministry of Education, University and Research published the Directive of 27 December 2012, entitled "Intervention tools for students with Special Educational Needs and territorial organization for school inclusion". It is important because it provides a series of guidelines, already present in the European Union, completing, in essence, the Italian framework of school inclusion (MEUR, 2012).

As is known, in fact, the Italian system was the first in Europe to introduce the mainstream education for all students with disabilities by the Law 104/92 and it has recently reorganized the principles of the same, with the Guidelines of August 4, 2009 (MEUR, 2009). Then, following the law $170 / 10$, issued the Guidelines of 12 July 2011, relating to the school inclusion of students with specific learning disorders or dyslexia, dysgraphia, dyscalculia and dysorthography. Nowadays, with a new Directive, the Ministry of Education, University and Research provides organizational indications on the inclusion of those students who are not certifiable or with 
disabilities or with learning difficulties, but who have learning difficulties due to personal disadvantage, family and socio-environmental (MEUR, 2012).

With the terms Special Educational Needs (hereafter SEN) mean exactly:

- students with disabilities;

- students with learning difficulties;

- students with socio-economic disadvantage, linguistic, cultural.

In all these types, the Directive of 27 december 2012 extends the benefits of the above mentioned Law n.170/10, namely the compensatory tools and dispensatory devices.

The Law obliges educational institutions to ensure the introduction of compensatory devices, including alternative learning and information technologies tools, as well dispensatory devices by some non-essential performance for the quality of the concepts to be learned.

The Law states that it is the teaching team that identifies the most suitable compensatory devices for students learning. It is good to agree on the use of these auxiliary aids with the family and with the student if he/she is an adult, so as to make he/she responsible and protagonists of his/her own learning process.

Specifically the compensatory devices are educational and technological tools which replaces or facilitates performance required in the deficient ability. These devices raise the student from the performance made hard by the disorder, allowing him/her to focus on more complex cognitive tasks. Obviously the knowledge of a subject not change, but the speed and accuracy of performance improve.

Same educational and technological compensatory tools are:

- Word processor;

- $\quad$ Speech Synthesis;

- $\quad$ Concept Maps;

- $\quad$ Audiobooks;

- $\quad$ Scanner with Optical character recognition OCR;

- $\quad$ Calculator with speech synthesis;

- $\quad$ Speech Recognition;

- $\quad$ Interactive White Board IWB;

- $\quad$ Dispensatory devices

- $\quad$ Digital foreign language Dictionaries

\section{Word Processor}

A word processor is an electronic device or computer software application, that performs the task of composition, editing, formatting, printing of documents. 
A word processor acts on self-determination of writing, on meta-skills and it helps the self-review and self-correction.

The real power of word processing lies in the way the computer can automate and simplify some aspects of the process of writing text. Cut, copy and paste for example allow us to move whole paragraphs, without having to re-type every word. In-built functions automatically format the document for us, correcting spelling mistakes as we make them. Documents can be created using any combination of text and images and some word processors even allow the addition of sounds, video clips and links to pages stored on the world wide web.

Text to speech technology used in other word processors can read out whole documents, single words or even individual letters as they are typed. It is little wonder then that computers are playing an increasing role in supporting the development of literacy skills, especially for those pupils with special educational needs.

Some examples are: Libre Office, Microsoft word, Carlo II, Superquaderno, Alfa Reader 3.0.

\section{Speech Synthesis}

Speech synthesis, commonly known as text-to-speech (TTS), is the artificial production of human speech. Nowadays there is a wide range of assistive technology (AT) tools available to help individuals who struggle with reading. While each type of tool works a little differently, all of these tools help by presenting text as speech. These tools help facilitate decoding, reading fluency, and comprehension.

\section{Concept Maps}

A concept map is a type of graphic organizer used to help students organize and represent knowledge of a subject. Concept maps begin with a main idea (or concept) and then branch out to show how that main idea can be broken down into specific topics.

Concept mapping serves several purposes for learners:

- $\quad$ helping students brainstorm and generate new ideas;

- $\quad$ encouraging students to discover new concepts and the propositions that connect them;

- $\quad$ allowing students to more clearly communicate ideas, thoughts and information;

- $\quad$ helping students integrate new concepts with older concepts;

- $\quad$ enabling students to gain enhanced knowledge of any topic and evaluate the information.

A concept map is also not just a learning tool, but an ideal evaluation tool for educators measuring the growth of and assessing student learning. As 
students create concept maps, they reiterate ideas using their own words and help identify incorrect ideas and concepts; educators are able to see what students do not understand, providing an accurate, objective way to evaluate areas in which students do not yet grasp concepts fully.

The two most popular free tools are: CmapTools and XMind.

\section{Audiobooks}

An audiobook (or talking book) is a recording of a text being read. In audiobooks, sentences are not spoken in isolation, as in traditional speech synthesis databases, which allow us to explore discourse-level effects in synthetic speech. Furthermore, audiobook readers often change their voices to impersonate certain characters or to convey particular emotions related to the text, essentially making their speech more expressive.

\section{Scanner with Optical character recognition OCR}

Optical character recognition (optical character reader, OCR) is the mechanical or electronic conversion of images of typed, handwritten or printed text into machine-encoded text, whether from a scanned document, a photo of a document, a scene-photo (for example the text on signs and billboards in a landscape photo) or from subtitle text superimposed on an image (for example from a television broadcast). It is a common method of digitizing printed texts so that they can be electronically edited, searched, stored more compactly, displayed on-line, and used in machine processes such as cognitive computing, machine translation, (extracted) text-to-speech, key data and text mining. OCR is a field of research in pattern recognition, artificial intelligence and computer vision.

In this way students can digitize all kinds of documents to be studied or read.

\section{Talking Calculator}

A talking calculator has a built-in speech synthesizer that reads aloud each number, symbol, or operation key a user presses; it also vocalizes the answer to the problem. This auditory feedback may help him check the accuracy of the keys he presses and verify the answer before he transfers it to paper.

Students with dyscalculia, which make errors in transcribing the data of a problem or a calculation, can use this tool to optimize time and to focus on the resolution procedures, rather than in the writing of the numbers or in the application of the calculation procedures. 


\section{Speech Recognition}

A speech recognition program works in conjunction with a word processor. The user "dictates" into a microphone, and his spoken words appear on the computer screen as text. This can help a user whose oral language ability is better than his writing skills.

Students with dysorthography can use these tools to verify written.

\section{Interactive White Board IWB}

An interactive whiteboard is an instructional tool that allows computer images to be displayed onto a board using a digital projector. The instructor can then manipulate the elements on the board by using his finger as a mouse, directly on the screen. Items can be dragged, clicked and copied and the lecturer can handwrite notes, which can be transformed into text and saved.

Some added tools to consider when using the whiteboards:

- highlighter;

- curtain;

- spotlight tools;

- various font options;

- magnifier tool;

- freehand shape and freehand text tools reinforce fine motor skill development for those with a dexterity disability;

- note taking for review of key concepts;

- recorded assignments that can be used to review lesson content and be saved, printed and taken home for additional reinforcement;

- audio or video supplements make information more accessible for emerging readers and ELL students;

- copies of board work and student/teacher notes can be captured and shared across the classroom or taken home for additional practice and review.

The widespread proliferation of IWBs for enhancing classroom teaching and learning stimulated a significant body of research into the manner of their use and their effectiveness on the student's attainment (Gray, HaggerVaughan, Pilkington \& Tomkins, 2010; Zambotti, 2009; Moss, Jewitt, Levačić et al., 2007). IWB technology has rapidly become an essential component of a modern classroom worldwide (Bonaiuti, 2009).

Research indicates that the use of IWBs in the classroom considerably increases student motivation and engagement in learning, particularly at the initial stages of the implementation (Demo, 2015; Higgins et al, 2007).

Interactive whiteboards brings in group learning, working together, collaboration and turn taking.

This type of tool promotes creative teaching and motivates students into absorbing information. 
Teaching with an interactive whiteboard allows lecturers to accommodate all different learning styles:

- $\quad$ tactile learners get to touch and move things around the board. They can also make notes and highlight elements;

- $\quad$ Visual learners benefit from a clear view of what is happening on the board;

- $\quad$ audio learners can participate in a class discussion.

IWBs are a powerful tool in the classroom adding interactivity and collaboration, allowing the integration of media content into the lecture and supporting collaborative learning. Used innovatively they create a wide range of learning opportunities for whole class, nobody excluded.

\section{Dispensatory devices}

Dispensatory devices are actions, or didactic strategies that allow students to not perform certain activities which, due the disorder, are particularly difficult and that are not essential for learning. E.g., it is not useful to read for a student with dyslexia a long passage, because the disorder does not improve his/her reading performance.

Same didactic strategies are:

- longer time for written tests and study;

- planning oral tests;

- small extent homework;

- being able to carry out a test on a significant content but reduced in quantity.

\section{Talking spell checkers and electronic dictionaries}

Talking spell checkers and electronic dictionaries can help a poor speller select or identify appropriate words and correct spelling errors during the process of writing and proofreading. Talking devices "read aloud" and display the selected words onscreen, so the user can see and hear the words".

Talking spell checkers and electronic dictionaries are very useful for pupils with dyslexia.

\section{Conclusion}

Using technology fosters belonging and interactive participation in general education classrooms for students with SEN (UNESCO, 2009; EADSNE, 2010b).

Technology increases the frequency of assignment completion and contributes to improved motivation (Striano, 2010; Calvani, 2007). It therefore supports some of the basic objectives of inclusive education: a sense of belonging to group, shared activities with individual outcomes, and a balanced educational experience. Adaptations for students with SEN have been widely used to compensate for barriers associated with difficulties in reading, writing, 
mathematical reasoning, and problem solving (Rotatori and al, 2014). Increased use of technology devices during cooperative learning activities can enhance the participation of students with SEN by circumventing specific disability related barriers. E.g. a student with spelling problems could use devices to check spelling or search for definitions during a cooperative writing project. Or else a student with dysorthography could use a portable note taker to ease his/her frustrations, increase his/her motivation to complete assignments, and make him/her feel more accepted by his peers in the general education classroom. Thus technology contributes to improved academic achievement.

The school staff facilitates the evaluation process by identifying students' strengths and the areas in which they are challenged in general education classrooms. In collaboration, the team determines an appropriate match among devices, setting- specific demands, and student characteristics (de Anna, Gaspari, Mura, 2015).

Technology can help students with SEN compensate for challenges in learning, especially in the area of writing, providing computer-supported tools. In addition, this technology can also ease frustration, increase motivation, foster a sense of peer acceptance, and improve productivity in the classroom and at home. The European Commission amendments specify that technology be considered in developing individualized educational plans (2010). Collaborative planning teams must develop a vision of technology for individual students and general education classrooms. Team members need to determine the effectiveness of current technology and closely monitor students to ensure that the necessary modifications are made to reflect the changing abilities of the individuals. The potential of technology for students has not been realized; the future is uncertain but holds much promise. For individuals with SEN, this technology can be one way to break down barriers to learning.

\section{References:}

Becta (2004). What the research says about ICT supporting special educational needs (SEN) and inclusion, Becta publications ID: BEC1-15009.

Retrieved from http://www.becta.org.uk/page_documents/research/wtrs_ictsupport.pdf. Becta (2007). Inclusive learning: an essential guide. Retrieved from http://publications.becta.org.uk/display.cfm?resID=27692\&page=1835.

Bonaiuti, G. (2009). Active education with IWB. Trento, Italy: Erickson. Calvani, A. (2007). Technology, school, cognitive processes. For an ecology of learning. Rome, Italy: Franco Angeli.

de Anna, L. (2014a). Special Pedagogy. Integration and Inclusion. Rome, Italy: Carocci. 
de Anna L. (2014b). Inclusive Education and "Special Pedagogy" the Italian Approach. Alter, European Journal of Disability Research, 8, 2.

de Anna, L. (2014c). The Inclusive School: roles and professions. Italian Journal of Special Education for Inclusion anno II | n. 2 | 2014.

de Anna, L., Gaspari, P., Mura, A. (eds) (2015). The specialized teacher. training courses for the profession. Rome, Italy: Franco Angeli.

Della Volpe, V. (2014), 'The Italian School: An Inclusive Context for Students with Disabilities', Bulletin of National Institute of Educational Resources and Research, Taipei-Taiwan R.O.C., vol. 62 "Secondary Education in the World 2013".

Della Volpe, V. (2016), Examination on ICT integration into Italian Inclusive Education. Education and E-learning: Open Access Received: Feb 29, 2016, Accepted: May 10, 2016, Published: May 14, 2016 Educ E-learn, Volume 1, Issue $1 \mathrm{http}: / /$ crescopublications.org/pdf/EEOA/EEOA-1-004.pdf Article Number: EEOA-1-004.

Demo, H. (ed) (2015). Didactic for differences. Methodological approaches for an inclusive classroom. Trento, Italy: Erickson.

European Agency for Development in Special Needs Education (EADSNE). (2010a). Inclusive education and classroom practice in secondary education: Literature review (Edited by Cor J.W. Meijer). Retrieved from http://www.europeanagency.org/publications/ereports/inclusiveeducationand-effective-classroom-practice/IECPsecondary-Literature-Review.pdf.

European Agency for Development in Special Needs Education (EADSNE). (2010b). Teacher Education for Inclusion. Retrieved from https://www.european-agency.org/sites/default/files/TE4I-Literature-

Review.pdf.

European Commission. (2010). European disability strategy 2010-2020: A Renewed commitment to a barrier-free Europe. Retrieved from http://eurlex.europa.eu/LexUriServ/LexUriServ.do?uri=COM:2010:0636:FIN:EN:PD F.

Gray, C., Hagger-Vaughan, L., Pilkington, R. \& Tomkins, S-A. (2010). The pros and cons of interactive whiteboards in relation to the key stage 3 strategy and framework. Language Learning Journal, 32, 38-44.

Higgins, S., Beauchamp, G. \& Miller, D. (2007). Reviewing the Literature on Interactive Whiteboards. Learning, Media and Technology, 32 (3), 213 - 225. Ministry of Education, University and Research (MEUR). (1992). Note n.39 Framework Law for assistance, social integration and rights for handicapped people.

Retrieved from http://hubmiur.pubblica.istruzione.it/alfresco/d/d/workspace/SpacesStore/b9b 27816-47b5-4031-9f4b-f0a8d1a8f364/prot104_92.pdf.

Ministry of Education, University and Research (MEUR). (2009). Note n.4274 Guidelines for school inclusion of students with disabilities. Retrieved 
from

http://hubmiur.pubblica.istruzione.it/alfresco/d/d/workspace/SpacesStore/115 c59e8-3164-409b-972b-8488eec0a77b/prot4274_09_all.pdf.

Ministry of Education, University and Research (MEUR). (2010). Law 08.10.2010 New rules on SEN. Retrieved from http://www.istruzione.it/esame_di_stato/Primo_Ciclo/normativa/allegati/legg e170_10.pdf.

Ministry of Education, University and Research (MEUR). (2011). Guidelines for the right to study of pupils and students with SEN. Retrieved from http://hubmiur.pubblica.istruzione.it/alfresco/d/d/workspace/SpacesStore/769 57d8d-4e63-4a21-bfef-

0b41d6863c9a/linee_guida_sui_dsa_12luglio2011.pdf.

Ministry of Education, University and Research (MEUR). (2012). Directive on SEN and territorial organization for school inclusion. Retrieved from http://hubmiur.pubblica.istruzione.it/alfresco/d/d/workspace/SpacesStore/8d3 1611f-9d06-47d0-bcb7-3580ea282df1/dir271212.pdf.

Moss, G, Jewitt, C, Levačić, R, Armstrong, V, Cardini, A, \& Castle, F. (2007). The Interactive Whiteboards, pedagogy and pupil performance evaluation: An Evaluation of the Schools Whiteboard Expansion (SWE) Project: London Challenge. Retrieved from http://www.dfes.gov.uk/research/data/uploadfiles/RR816.pdf.

Mura, A. (2012). Special Pedagogy. Rome, Italy: Franco Angeli.

Pavone, M. (2014). The inclusive education. Pedagogical recommendations for disability. Bologna, Italy: Mondadori University.

Rotatori, A. F., Bakken, J.P., Obiakor, F. (2014). Special Education International Perspectives: Practices Across the Globe. Emerald: UK

Striano, M. (ed) (2010). Educational practices for social inclusion. Rome, Italy: Franco Angeli.

UNESCO (2009). Policy Guidelines on Inclusion in Education. Paris: UNESCO.

UNESCO (2014). L'education inclusive: une formation à inventer. Actes du Colloque International UNESCO. Paris, 17-18 octobre 2013, IIPE, Paris.

United Nations. (2006). The convention on the rights of persons with disabilities. $\quad$ Retrieved from http://www.un.org/disabilities/convention/conventi onfull.shtml.

Zambotti, f. (2009). Inclusive education with IWB. Trento, Italy: Erickson. 